\title{
Zika virus detection, isolation and genome sequencing through Culicidae sampling during the epidemic in Vitória, Espírito Santo, Brazil
}

\author{
Constância Flavia Junqueira Ayres ${ }^{1 *}$, Duschinka Ribeiro Duarte Guedes ${ }^{1}$, Marcelo Henrique Santos Paiva ${ }^{1,2}$, \\ Mariana Carolina Morais-Sobral ${ }^{1}$, Larissa Krokovsky ${ }^{1}$ Laís Ceschini Machado ${ }^{1}$, Maria Alice Varjal Melo-Santos ${ }^{1}$, \\ Mônica Crespo', Cláudia Maria Fontes Oliveira1, Ricardo Silva Ribeiro³, Orlei Amaral Cardoso33, \\ Ana Lúcia Barbosa Menezes ${ }^{4}$, Roberto Costa Laperrière-Jr ${ }^{5}$, Carlos Feitosa Luna ${ }^{6}$, André Luiz Sá Oliveira ${ }^{6}$, \\ Walter Soares Leal ${ }^{7}$ and Gabriel Luz Wallau ${ }^{1}$
}

\begin{abstract}
Background: Zika virus (ZIKV) has been isolated from many mosquito species in nature, but it is believed that the main vectors in urban environments are species of the genus Aedes. Here, we detected and isolated ZIKV in samples from Aedes aegypti, Aedes taeniorhynchus and Culex quinquefasciatus, collected during the Zika epidemic in Vitória, southeast Brazil. Using quantitative real-time polymerase chain reaction, ZIKV detection was performed in mosquito samples collected from February to April 2016.
\end{abstract}

Results: Overall, six pools of mosquitoes were positive for ZIKV: four of $C X$. quinquefasciatus, one of Ae. aegypti and one of Ae. taeniorhynchus. Their genomes were sequenced.

Conclusions: These results support and strengthen the hypothesis that other mosquito species can also be involved in ZIKV transmission.

Keywords: Field-caught mosquitoes, Zika virus, RT-qPCR, Genome sequencing

\section{Background}

In 2015-2016, the world faced the spread of a global epidemic caused by Zika virus (ZIKV). This arbovirus (arthropod-borne virus) was first identified in Uganda in 1947 from sentinel monkeys but remained unnoticed in humans until 60 years later [1]. In 2007, a Zika outbreak was reported in Micronesia, affecting $73 \%$ of the inhabitants, followed by a new outbreak in French Polynesia in 2013 , which affected $70 \%$ of the population [2, $3]$. Despite these reports, no severe consequences of ZIKV infections in humans had been described until its

\footnotetext{
*Correspondence: tans@cpqam.fiocruz.br

${ }^{1}$ Departamento de Entomologia, Instituto Aggeu Magalhães (IAM),

Fundação Oswaldo Cruz, Recife, Brasil

Full list of author information is available at the end of the article
}

arrival in South America. In this continent, ZIKV infections were associated with birth defects, due to motherto-child transmission of the virus, such as microcephaly and other neurological disorders, which are now collectively referred to as "congenital Zika syndrome" $[4,5]$. In addition, ZIKV is also capable of triggering neurological abnormalities, such as Guillain-Barré syndrome [6]. From a mild disease before 2015 to an epidemic that has a diverse impact on population health, in 2016 the World Health Organization (WHO) declared Zika a public health emergency of international concern [7].

The ZIKV is a positive-sense, single-stranded RNA virus, with a genome length of approximately $11 \mathrm{~kb}$, which codes for a single polyprotein [3] composed of three structural proteins: capsid (C), pre-membrane (prM) and envelope (E); as well as seven nonstructural 
proteins: NS1, NS2a, NS2b, NS3, NS4a, NS4b and NS5 [8]. The structural proteins are responsible for the formation of the virus particle, while non-structural proteins are responsible for important functions in genome replication, polyprotein processing and host response [9]. ZIKV transmission primarily occurs through bites from infected mosquitoes, but unlike other arboviral diseases, other non-vector-borne transmission pathways have been reported, such as blood transfusion, sexual transmission, transplacental infection and breastfeeding [1013]. In addition, studies have demonstrated the presence and persistence of infective ZIKV in saliva, urine and semen $[8,14]$.

Aedes aegypti is considered the main vector of ZIKV along with Aedes albopictus [15-18]. However, Culex quinquefasciatus, the most common mosquito in urban areas of the southern hemisphere, also known as the southern house mosquito, was implicated in ZIKV transmission during recent epidemics [19]. This mosquito's vector competence has been recently demonstrated under laboratory conditions by three different groups
[20-22], as well as in field samples, when ZIKV was isolated from two pools of $C x$. quinquefasciatus mosquitoes from Recife (northeast region), and from several pools collected in Guadalajara, Mexico [23].

Here, we report the results of a study conducted in early 2016 to detect ZIKV in field-caught mosquitoes collected in the city of Vitória, Espírito Santo, Brazil.

\section{Results}

Aspirations resulted in the highest number of collected mosquitoes among the three collection methods: $C x$. quinquefasciatus $(n=223)$, Ae. aegypti $(n=12)$, Aedes taeniorhynchus $(n=6)$ and Aedes scapularis $(n=1)$. Culex quinquefasciatus was also the most abundant mosquito collected in CDC traps $(n=47)$, followed by $A e$. taeniorhynchus $(n=19)$. No other Aedes species were collected in CDC traps. New Jersey traps collected more Ae. taeniorhynchus $(n=20)$ than $C x$. quinquefasciatus $(n=16)$ and Ae aegypti $(n=2)$. Figure 1 shows the distribution of sites where mosquitoes were captured and positive pools were detected.

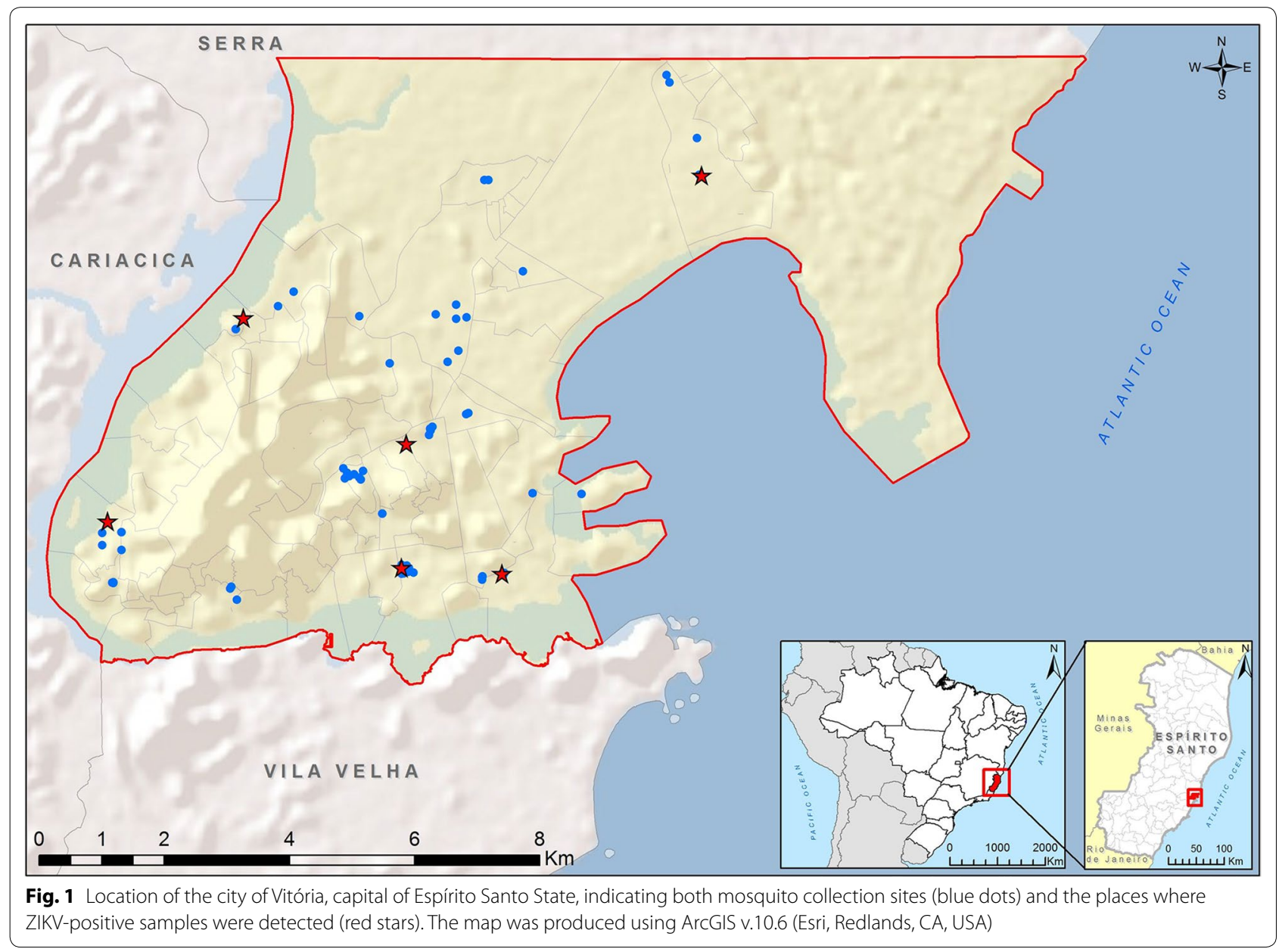


A total of 346 mosquitoes were analyzed in 95 pools, of which 25 (26\%) contained mosquito females that had recently taken a blood meal, and $70(74 \%)$ contained mosquito females without visible blood remains in the abdomen. Six pools from the second group (non-fed mosquitoes) were positive for ZIKV (Table 1).

ZIKV was isolated after the first passage in Vero cells from three out of the six positive pools collected in Vitória (two were obtained from $C x$. quinquefasciatus and one from Ae. aegypti). None of these pools showed signs of recent blood-feeding. These genomes were named ZIKV/C. quinquefasciatus/Brazil/ES01/2016 (Cxq_ES1), ZIKV/C. quinquefasciatus/Brazil/ES24/2016 (Cxq_ES24) and ZIKV/Ae. aegypti/Brazil/ES32/2016 (Aea_ES32). Sequencing efforts obtained partial ZIKV genomes, which were aligned against all ZIKV genomes available from Faria et al. [24]. ZIKV partial genomes are available in the figshare website, as NGS reads (https:// figshare.com/s/965be7f2e89dafa8885a). These genomes presented a $44 \%$ (4745) coverage breath for Cxq_ES1, 57\% (6157) for Cxq_ES24 and 55\% (5948) for Aea ES32 (Fig. 2). The coverage depth obtained ranged from $19 \times$ for Aea_ES32 to 1029x for Cxq_ES1, with Cxq_ES24 sequenced at an intermediate depth of approximately $222 \times$.

Phylogenetic analysis of all available ZIKV genomes revealed that two sequenced ZIKV genomes (Cxq_ES24 and Aea_ES32) clustered with an early clade of ZIKV detected in Haiti in 2014 and in Pernambuco state in 2015 (Fig. 3) [full maximum likelihood tree can be seen on the Interactive Tree of Life website (https://itol.embl. de/tree/19118716467351551538327490)]. In addition, the Cxq_ES1 ZIKV genome clustered within one of the major ZIKV branches that caused the 2015 epidemic in Brazil (Fig. 3). Of note, Cxq_ES24 draft genome differed by seven single nucleotide polymorphisms (SNPs) from the reference PE243 genome [25], while Aea_ES32 differed by 12 SNPs from the PE243 ZIKV genome. Because Cxq_ES1 clustered together with strains of another clade, we compared it with the Paraíba ZIKV genome (KX280026) and observed the presence of seven SNPs.
Considering all complete and draft genomes of ZIKV used in the alignments, the sequences obtained in this study showed non-exclusive SNPs, that is, such variants also occurred in most ZIKV genomes from the 20152016 epidemic (data not shown).

\section{Discussion}

In this study, we report the detection of ZIKV in fieldcaught mosquitoes from Vitória, (ES), during part of the 2016 epidemic. ZIKV was found in three different species, namely Ae. aegypti, Ae. taeniorhynchus and $C x$. quinquefasciatus. This is the first report of ZIKV detection in species other than Ae. aegypti in southeast Brazil.

The identification of ZIKV mosquito vectors has been the subject of a heated debate. The proof-of-principle study performed by Guo et al. [21] demonstrated that transmission by $C x$. quinquefasciatus is feasible, but only evidence collected in natural settings, such as during outbreaks, can demonstrate how this species contributes to ZIKV spread. Unfortunately, despite the very high incidence of Zika in human populations, there is a lack of data regarding the spatial and temporal association of human cases and local vector abundance, preventing us from concluding which mosquito species plays the dominant role in ZIKV transmission in this urban context. From the 81 countries reporting recent ZIKV outbreaks, it was only possible in three (Brazil, Mexico and USA) to detect ZIKV circulating in vector populations. In Brazil, ZIKV has been detected in Ae. aegypti from Rio de Janeiro [26] and in Ae. aegypti and Cx. quinquefasciatus from Recife [20]. In Mexico, 15 out of 58 pools of Ae. aegypti were found positive for ZIKV in Chiapas state [27]. In Guadalajara, Mexico, ZIKV has been isolated from several mosquito species, especially $C x$. quinquefasciatus [23]. Before the recent ZIKV outbreaks, Culex perfuscus was found naturally infected with ZIKV in Senegal and this species displayed a MIR tenfold higher than $A e$. aegypti [28].

The results obtained here give further support for the role of both Ae. aegypti and Cx. quinquefasciatus in the ZIKV transmission. Our group also reported in

Table 1 Zika virus infection of potential vectors collected in Vitória-ES

\begin{tabular}{|c|c|c|c|c|c|}
\hline Mosquito species & No. of pools & $\begin{array}{l}\text { No. of females (no. of } \\
\text { non-fed females) }\end{array}$ & Positive pools (Ct values) & Sampling method & $M I R^{a}$ \\
\hline Ae. aegypti & 8 & $14(5)$ & $1(37.1)$ & Aspiration & 200 \\
\hline Ae.taeniorhynchus & 27 & $45(1)$ & $1(37.0)$ & CDC & 22.72 \\
\hline Ae. scapularis & 1 & $1(0)$ & 0 & - & - \\
\hline Cx. quinquefasciatus & 59 & $286(102)$ & $4(37.3 ; 37.2 ; 37 ; 37.9)$ & CDC (1), NJ (1), aspiration (2) & 39.2 \\
\hline Total & 95 & 346 & 6 & & - \\
\hline
\end{tabular}

${ }^{a}$ MIR was calculated using pools that contained only non-blood-fed females 


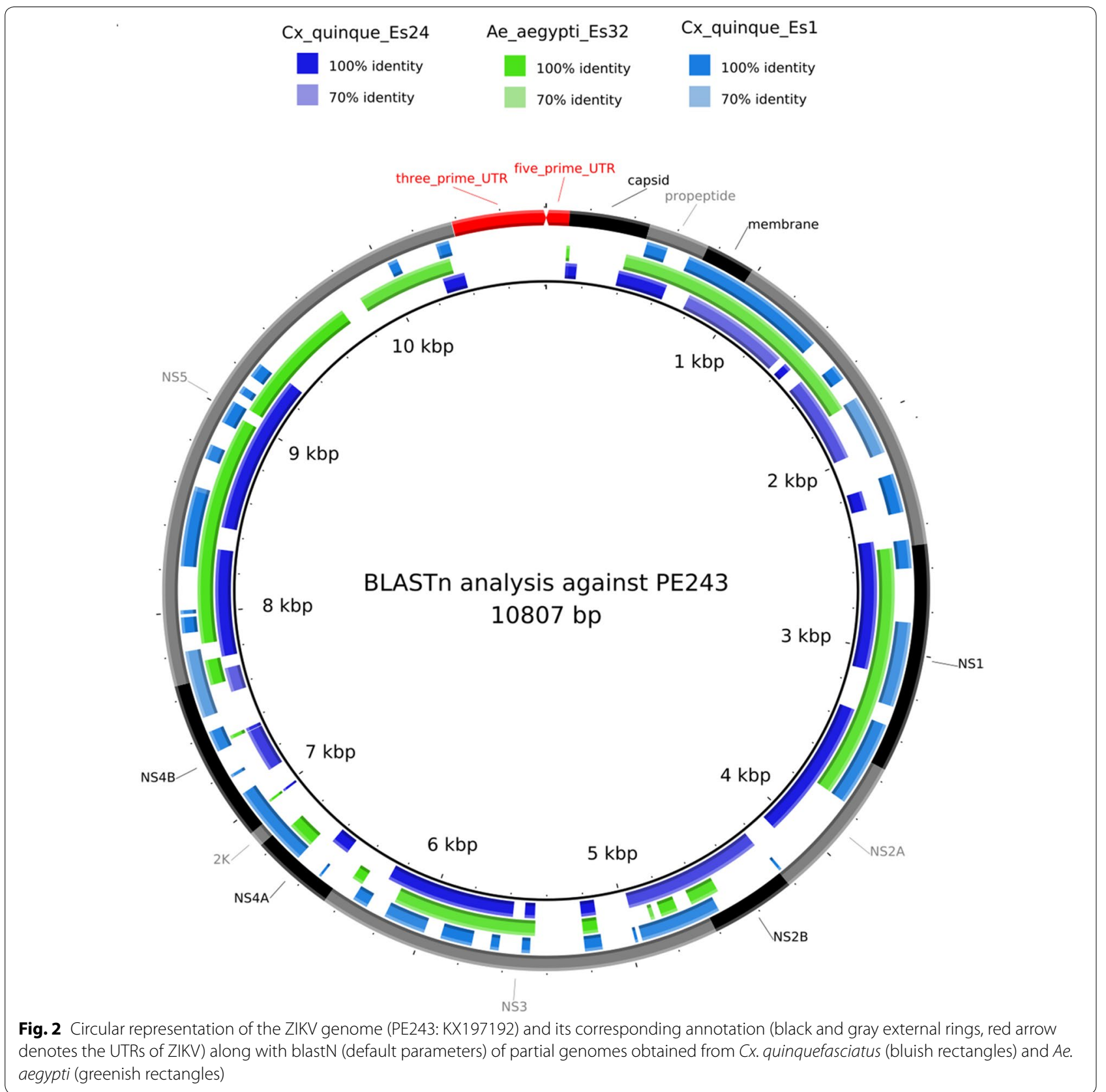

a previous paper that $C x$. quinquefasciatus plays an important role in ZIKV spread in Brazil through laboratory and field experiments [20]. On the other hand, several research groups have conducted vector competence studies of Culex and Aedes mosquitoes and demonstrated that Culex species are not competent to transmit ZIKV [29-34]. The nature of these conflicting results should be investigated in more detail, as different explanations have been suggested [35, 36]. A study conducted in Florida, USA, to identify the pattern of host use by mosquito species, suggested that $C x$. quinquefasciatus plays a secondary role in ZIKV transmission, and that Ae. aegypti and Ae. albopictus are the most likely ZIKV vectors. The authors concluded that the relative importance of each species in spreading the virus may vary according to specific location and population [37].

Considering that $C x$. quinquefasciatus may play a role in ZIKV transmission, it is crucial to highlight the distinct biological traits displayed by Culex and Aedes mosquitoes. The population distribution of these mosquitoes 


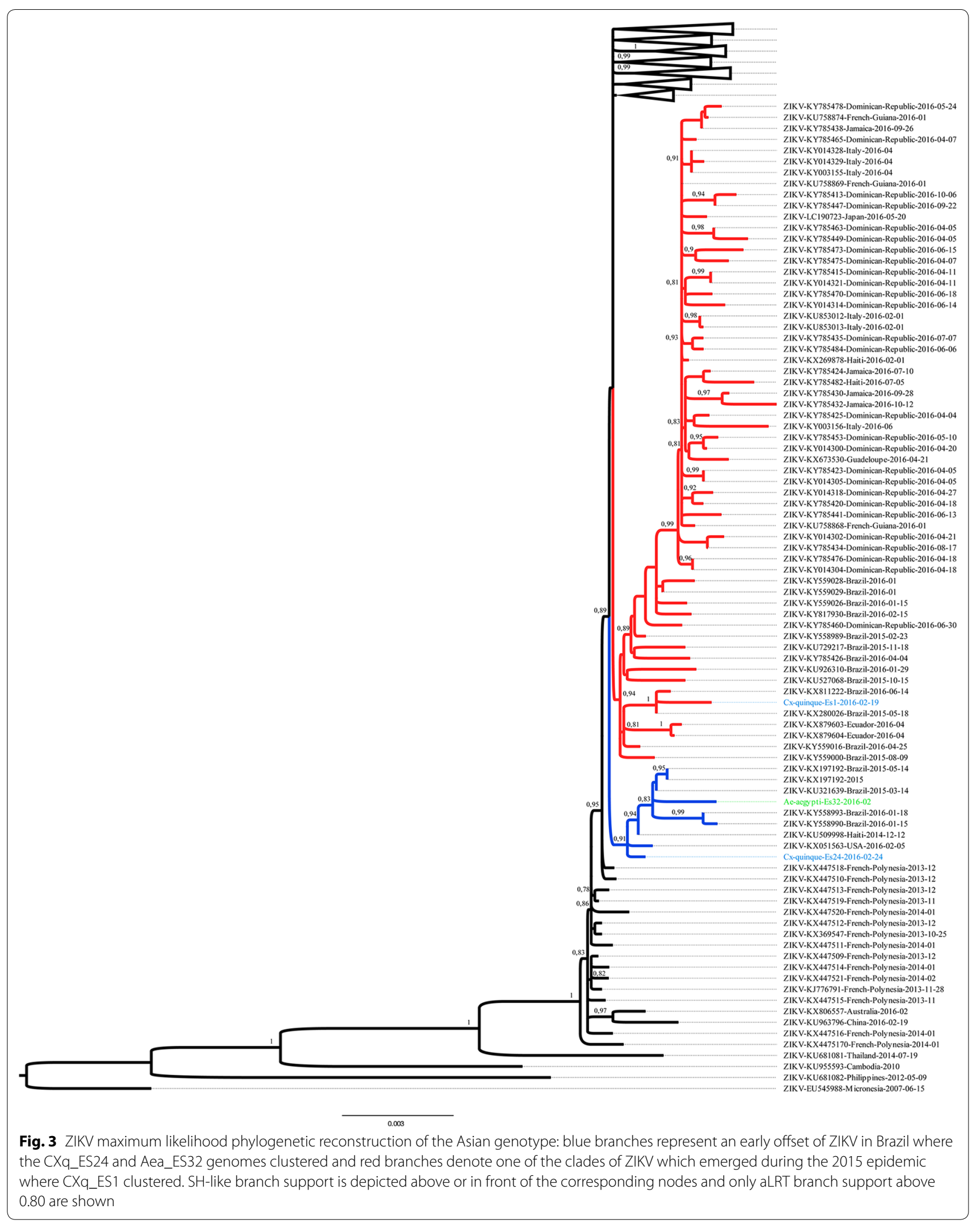


differs in most Brazilian cities and most tropical countries; Cx. quinquefasciatus is approximately 20 times more abundant than Aedes as shown previously [38, 39]. In addition, $C x$. quinquefasciatus females show different feeding behavior when compared to Ae. aegypti females. Usually, an $A e$ e aegypti female can feed on multiple hosts until its gonotrophic cycle is complete [40], while $C x$. quinquefasciatus usually feed on only one host [41]. This behavior increases the potential for Ae. aegypti to become infected compared to $C x$. quinquefasciatus.

On the other hand, $C x$. quinquefasciatus mosquitoes in the southern hemisphere exhibit a highly anthropophilic feeding behaviour. In Brazil, this species is solely responsible for the active transmission of Wuchereria bancrofti, the lymphatic filariasis causative agent [42]. It has also been implicated as a potential vector in the transmission of Oropouche virus (OROV), in the state of Mato Grosso [43], which was considered the second most common arbovirus in Brazil [43, 44].

In this study, we detected a pool of Ae. taeniorhynchus positive for ZIKV, but we were unable to isolate and sequence the ZIKV from this pool. Aedes taeniorhynchus is a common species found along the Brazilian coastline, and it is implicated as the primary vector of canine heartworm disease in the northeastern and southeastern regions of the country [45]. In addition, it has been identified as the primary vector of Venezuelan equine encephalitis [46] and as a potential vector for maintaining the transmission cycle of West Nile fever (WNV) in the Galapagos [47]. Further studies are necessary to better understand if Ae. taeniorhynchus play a role in ZIKV transmission among human.

In order to obtain detailed information about the viral strains circulating in this region we performed isolation of ZIKV from field-caught mosquitoes and sequenced their genome. Bioinformatics analysis showed that these strains were clustered into two distinct clades. The first comprised Cxq_ES24 and Aea_ES32 along with the virus Brazil PE243 2015 (from Pernambuco state), Haiti 1225 2014 and SPH2015 (from São Paulo state). This clade encompasses the first group of ZIKV strains identified in northeast Brazil. The second clade clustered Cxq_ES1 with several other strains reported in the southeast and northeast Brazil. Interestingly, the detection of strains from the first clade in other Brazilian state, besides Pernambuco and São Paulo, shows that those variants also are circulating and spreading very rapidly in comparison to the other epidemic clades [24].

Previous data suggest that ZIKV is a very fast-evolving and adaptive virus, and we should not expect it to fit into previously described simple models (i.e. one pathogenone vector). Instead, the scientific community should keep an open mind [48] and focus on understanding the ecology of ZIKV and its interactions with different host cells (i.e. human, non-human vertebrates and mosquitoes) to elucidate its amplification cycles in urban environments and to prevent new ZIKV outbreaks and its associated neurological diseases.

\section{Conclusions}

Results found in this study confirm the detection of ZIKV in field-caught mosquitoes from Vitória, Espírito Santo (ES) in three different mosquito species (Ae. aegypti, Ae. taeniorhynchus and Cx. quinquefascitus). Additionally, this is the first report of ZIKV detection in species other than Ae. aegypti in the studied area. Furthermore, it was observed that ZIKV strains were clustered into two distinct clades, showing that these variants are co-circulating and spreading very rapidly. Thus, it is of utmost importance to detect and monitor the emergence and spread of ZIKV in the country to implement successful surveillance strategies.

\section{Methods \\ Study site}

Vitória is the capital of Espírito Santo, a state located in the southeastern region of Brazil (Fig. 3). This municipality is a river-oceanic archipelago of $63,396 \mathrm{~km}^{2}$, consisting of 35 islands and a mainland region with an estimated population of almost 360,000 inhabitants [23, 49]. Approximately $40 \%$ of its area is covered by hills. Vitória comprises 80 neighborhoods, grouped into nine administrative regions. The city is considered the second best Brazilian capital with respect to quality of life indicators. The climate in Vitória is tropical with two distinguishable periods: the wet season from October to December and the sub-dry season from January to September. The exception is August, which is the driest month of the year.

\section{Mosquito collections}

Adult female mosquitoes were collected from February to April 2016 using three different methods: New Jersey and CDC light traps and battery-powered aspirators. Thirtyseven CDC light traps, with white lights, were installed for surveillance and control of Culex spp. in 35 neighborhoods in Vitória. In addition, nine New Jersey light traps were installed in other districts that had reported high numbers of Zika cases. All traps were installed outdoors at public building properties, to facilitate access for the community health agents at the time of sample collection. Traps were turned on late in the afternoon and disconnected early the next morning after sample collection.

Battery-powered aspirators were also employed during daytime for capturing adult female mosquitoes in schools, hospitals, basic healthcare units and residences, 
to block Zika transmission in areas where Zika cases had been reported. Mosquitoes caught in New Jersey and CDC light traps were collected by vector control staff members, while municipal health agents involved in combating endemic diseases performed aspirations. Samples were identified from the traps and transported to the laboratory immediately after collection. After being anaesthetized at $-20{ }^{\circ} \mathrm{C}$ for $10 \mathrm{~min}$, mosquitoes were placed on Petri dishes on ice and sorted by species, sex, date and location. Females were pooled into 1.5 $\mathrm{ml}$ microtubes with a maximum of 20 females per tube. Then, $100 \mu \mathrm{l}$ of RNAlater ${ }^{\mathrm{TM}}$ stabilization solution was added to each sample, which were then covered with cotton balls and stored at $-20{ }^{\circ} \mathrm{C}$. In September 2016, samples were shipped to Aggeu Magalhães Institute (FIOCRUZ-PE) in Recife, in portable thermal iceboxes filled with dry ice.

\section{RNA extraction and RT-qPCR}

After registering feeding status, mosquitoes were repooled into groups of a maximum of 10 specimens. RNA extractions and ZIKV molecular detection (RT-qPCR description and protocol) are described in Guedes et al. [20] and in Lanciotti et al. [3]. All samples were tested in duplicate. A reference sample (ZIKV BRPE243/2015 RNA) was used as a positive control, and a negative control consisted of RNA from a known ZIKV-negative mosquito pool. Both positive and negative controls were used in all RT-qPCR assays.

\section{Minimum infection rate (MIR)}

To estimate viral infection rates in mosquito samples, we calculated the minimum infection rate (MIR), which is the number of positive pools divided by the total number of specimens tested and multiplied by 1000 as previously described [50].

\section{Spatial analysis}

Collection sites were georeferenced based on an address geocoding method that transforms residential addresses registered in a tabular database into geographic coordinates, by first using a database of streets stored in a digital cartographic base and then converting them to geographical coordinates (latitude and longitude) using QGIS, a free geographical information system (GIS) software. Therefore, georeferenced information was derived by registering each address displaying an associated geographical coordinate for each location. ArcGIS v.10.6 was used to create a map.

\section{Isolation and sequencing of ZIKV from field-collected samples}

ZIKV-positive pools from non-fed mosquitoes were used to recover ZIKV strains according to the protocol described in Guedes et al. [20]. To obtain ZIKV genomic sequences from positive samples, we performed the conditions described in the ZIBRA project protocol V3 [51]. PCR products were quantified using a Qubit dsDNA HS Assay Kit (Thermo Fisher Scientific Inc., Waltham, USA). MiSeq (Illumina, San Diego, CA, USA) sequencing libraries were prepared with a Nextera XT Library Prep Kit (Illumina) using $2 \mathrm{ng}$ of input cDNA derived from the ZIKV multiplex PCR, following manufacturer's instructions. MiSeq Reagent Kit V3 (Illumina; 150 cycles) was used in a paired-end strategy, resulting in $75 \mathrm{bp}$ reads separated from each other by ca. 350 bp. Sequencing was performed in a MiSeq instrument (Illumina) from the Technological Platform Core at Aggeu Magalhães Institute.

\section{ZIKV genome analysis}

Low quality raw reads, adaptors and ZIKV primers were trimmed with Trimmomatic v 0.36 [52], using the ILLUMINACLIP parameter. Bowtie2 [53] was used to map reads against the reference genome PE243 (KX197192.1) and consensus sequences were generated with Integrated Genome Viewer (IGV) [54, 55], considering only regions with coverage depth higher than $5 x$.

\section{Phylogenetic analysis}

Phylogenetic reconstruction was performed with PhyML 3.0 [56] using the GTR + I+G nucleotide substitution models suggested by the SMART model selection [57]. The tree topology search was performed with NNIs and SPRs [58]. Branch support was evaluated with the aLRT [59]. A total of $255 \mathrm{draft}$ and complete available ZIKV genomes, were collected from NCBI (https://www.ncbi. nlm.nih.gov/) up to December 2017, aligned with Mafft online service [60] and manually edited to keep only the ZIKV coding region. Figure generation was performed with FigTree (http://tree.bio.ed.ac.uk/software/figtree/).

\section{Abbreviations \\ ZIKV: Zika virus; RT-qPCR: quantitative real-time polymerase chain reaction; WHO: World Health Organization; CDC: Centers for Disease Control and Prevention; Ct: threshold cycle; MIR: minimum infection rate; SNP: single nucleotide polymorphisms; OROV: Oropouche virus; WNV: West Nile virus.}

\section{Acknowledgements}

We thank the Programme for Technological Development in Tools for Health (PDTIS-FIOCRUZ) for assistance with sequencing and real-time PCR.

\section{Funding}

This study was supported by the Fundação de Amparo à Ciência e Tecnologia do Estado de Pernambuco (FACEPE APQ-0078-2.02/16 and APQ-0085-2.13/16), 
the Brazilian National Council for Research and Development (CNPq; grant 441100/2016-3) and the National Institute of Allergy and Infectious Diseases at the National Institutes of Health (R21Al128931).

\section{Availability of data and materials}

The datasets used and/or analyzed during the present study are available from the corresponding author upon reasonable request.

\section{Authors' contributions}

CFJA, DRDG, MHSP, MAVMS, CMFO, WSL and GLW designed the initial project. RSR, OAC, ALBM and RCL collected mosquito samples in Vitória, ES. MCMS, LK, LCM, MC conducted laboratory experiments. CFL and ALSO performed the spatial analysis. CFJA, DRDG, MHSP, MAVMS, CMFO, WSL and GLW analyzed the results, interpreted data, and drafted the manuscript. All authors read and approved the final manuscript.

\section{Ethics approval and consent to participate}

Not applicable.

\section{Consent for publication}

Not applicable.

\section{Competing interests}

The authors declare that they have no competing interests.

\section{Publisher's Note}

Springer Nature remains neutral with regard to jurisdictional claims in published maps and institutional affiliations.

\section{Author details}

${ }^{1}$ Departamento de Entomologia, Instituto Aggeu Magalhães (IAM), Fundação Oswaldo Cruz, Recife, Brasil. ${ }^{2}$ Universidade Federal de Pernambuco, Caruaru, Brasil. ${ }^{3}$ Núcleo de Vigilância em Saúde, Superintendência Regional de Saúde de Vitória, Cariacica, Brasil. ${ }^{4}$ Centro de Vigilância em Saúde Ambiental, Secretaria Municipal de Saúde, Vitória, Brasil. ${ }^{5}$ Núcleo Especial de Vigilância Ambiental, Gerência Estratégica de Vigilância em Saúde, Secretaria de Estado da Saúde, Vitória, Brasil. ${ }^{6}$ Núcleo de Estatística e Geoprocessamento (NEG), Instituto Aggeu Magalhães (IAM), Fundação Oswaldo Cruz, Recife, Brazil. ${ }^{7}$ Department of Molecular and Cellular Biology, University of California, Davis, USA.

Received: 24 October 2018 Accepted: 27 April 2019 Published online: 08 May 2019

\section{References}

1. Basu R, Tumban E. Zika virus on a spreading spree: what we now know that was unknown in the 1950's. Virol J. 2016;13:165.

2. Duffy MR, Chen TH, Hancock WT, Powers AM, Kool JL, Lanciotti RS, et al. Zika virus outbreak on Yap Island, Federated States of Micronesia. N Engl J Med. 2009;360:2536-43.

3. Lanciotti RS, Kosoy OL, Laven JJ, Velez JO, Lambert AJ, Johnson AJ, et al. Genetic and serologic properties of Zika virus associated with an epidemic, Yap State, Micronesia, 2007. Emerg Infect Dis. 2008;14:1232-9.

4. Del Campo M, Feitosa IM, Ribeiro EM, Horovitz DD, Pessoa AL, Franca GV, et al. The phenotypic spectrum of congenital Zika syndrome. Am J Med Genet A. 2017;173:841-57.

5. Miranda-Filho DB, Martelli CM, Ximenes RA, Araujo TV, Rocha MA, Ramos $\mathrm{RC}$, et al. Initial description of the presumed congenital Zika syndrome. Am J Public Health. 2016;106:598-600.

6. Oehler E, Watrin L, Larre P, Leparc-Goffart I, Lastere S, Valour F, et al. Zika virus infection complicated by Guillain-Barre syndrome-case report, French Polynesia, December 2013. Euro Surveill. 2014;19:20720.

7. Lowe R, Barcellos C, Brasil P, Cruz OG, Honorio NA, Kuper H, et al. The Zika virus epidemic in Brazil: from discovery to future implications. Int J Environ Res Public Health. 2018;15:E96.

8. Lindenbach BD, Rice CM. Molecular biology of flaviviruses. Adv Virus Res. 2003;59:23-61
9. Shi W, Zhang Z, Ling C, Carr MJ, Tong Y, Gao GF. Increasing genetic diversity of Zika virus in the Latin American outbreak. Emerg Microbes Infect. 2016;5:e68.

10. Aubry M, Finke J, Teissier A, Roche C, Broult J, Paulous S, et al. Seroprevalence of arboviruses among blood donors in French Polynesia, 2011-2013. Int J Infect Dis. 2015;41:11-2.

11. Besnard M, Lastere S, Teissier A, Cao-Lormeau V, Musso D. Evidence of perinatal transmission of Zika virus, French Polynesia, December 2013 and February 2014. Euro Surveill. 2014;19:20751.

12. Dupont-Rouzeyrol M, Biron A, O'Connor O, Huguon E, Descloux E. Infectious Zika viral particles in breastmilk. Lancet. 2016;387:1051.

13. Foy BD, Kobylinski KC, Chilson Foy JL, Blitvich BJ, Travassos da Rosa TA, Haddow $A D$, et al. Probable non-vector-borne transmission of Zika virus, Colorado, USA. Emerg Infect Dis. 2011;17:880-2.

14. Bonaldo MC, Ribeiro IP, Lima NS, Dos Santos AA, Menezes LS, da Cruz SO, et al. Isolation of infective Zika virus from urine and saliva of patients in Brazil. PLoS Negl Trop Dis. 2016;10:e0004816.

15. Araujo AP, Araujo Diniz DF, Helvecio E, de Barros RA, de Oliveira CM, Ayres $C F$, et al. The susceptibility of Aedes aegypti populations displaying temephos resistance to Bacillus thuringiensis israelensis: a basis for management. Parasit Vectors. 2013;6:297.

16. Chouin-Carneiro T, Vega-Rua A, Vazeille M, Yebakima A, Girod R, Goindin D, et al. Differential susceptibilities of Aedes aegypti and Aedes albopictus from the Americas to Zika virus. PLoS Negl Trop Dis. 2016;10:e0004543.

17. Grard G, Caron M, Mombo IM, Nkoghe D, Mboui Ondo S, Jiolle D, et al. Zika virus in Gabon (Central Africa) - 2007: a new threat from Aedes albopictus? PLoS Negl Trop Dis. 2014:8:e2681.

18. Smartt CT, Stenn TMS, Chen TY, Teixeira MG, Queiroz EP, Souza Dos Santos $L$, et al. Evidence of Zika virus RNA fragments in Aedes albopictus (Diptera: Culicidae) field-collected eggs from Camacari, Bahia, Brazil. J Med Entomol. 2017:54:1085-7.

19. Ayres CF. Identification of Zika virus vectors and implications for control. Lancet Infect Dis. 2016;16:278-9.

20. Guedes DR, Paiva MH, Donato MM, Barbosa PP, Krokovsky L, Rocha S, et al. Zika virus replication in the mosquito Culex quinquefasciatus in Brazil. Emerg Microbes Infect. 2017;6:e69.

21. Guo XX, Li CX, Deng YQ, Xing D, Liu QM, Wu Q, et al. Culexpipiens quinquefasciatus: a potential vector to transmit Zika virus. Emerg Microbes Infect. 2016:5:e102.

22. Smartt CT, Shin D, Kang S, Tabachnick WJ. Culex quinquefasciatus (Diptera: Culicidae) from Florida transmitted Zika virus. Front Microbiol. 2018;9:768.

23. Elizondo-Quiroga D, Medina-Sanchez A, Sanchez-Gonzalez JM, Eckert KA Villalobos-Sanchez E, Navarro-Zuniga AR, et al. Zika virus in salivary glands of five different species of wild-caught mosquitoes from Mexico. Sci Rep. 2018;8:809.

24. Faria NR, Quick J, Claro IM, Theze J, de Jesus JG, Giovanetti M, et al. Establishment and cryptic transmission of Zika virus in Brazil and the Americas. Nature. 2017;546:406-10.

25. Donald CL, Brennan B, Cumberworth SL, Rezelj VV, Clark JJ, Cordeiro MT, et al. Full genome sequence and sfRNA interferon antagonist activity of Zika virus from Recife, Brazil. PLoS Negl Trop Dis. 2016;10:e0005048.

26. Ferreira-de-Brito A, Ribeiro IP, Miranda RM, Fernandes RS, Campos SS, Silva KA, et al. First detection of natural infection of Aedes aegypti with Zika virus in Brazil and throughout South America. Mem Inst Oswaldo Cruz. 2016;111:655-8.

27. Guerbois M, Fernandez-Salas I, Azar SR, Danis-Lozano R, Alpuche-Aranda CM, Leal G, et al. Outbreak of Zika virus infection, Chiapas State, Mexico, 2015, and first confirmed transmission by Aedes aegypti mosquitoes in the Americas. J Infect Dis. 2016;214:1349-56.

28. Diallo D, Sall AA, Diagne CT, Faye O, Faye O, Ba Y, et al. Zika virus emergence in mosquitoes in southeastern Senegal, 2011. PLoS One. 2014:9:e109442.

29. Amraoui F, Atyame-Nten C, Vega-Rua A, Lourenco-de-Oliveira R, Vazeille $M$, Failloux $A B$. Culex mosquitoes are experimentally unable to transmit Zika virus. Euro Surveill. 2016;21:30333.

30. Boccolini D, Toma L, Di Luca M, Severini F, Romi R, Remoli ME, et al. Experimental investigation of the susceptibility of Italian Culexpipiens mosquitoes to Zika virus infection. Euro Surveill. 2016;21:30328.

31. Fernandes RS, Campos SS, Ferreira-de-Brito A, Miranda RM, Barbosa da Silva KA, Castro MG, et al. Culex quinquefasciatus from Rio de Janeiro 
is not competent to transmit the local Zika virus. PLoS Negl Trop Dis. 2016;10:e0004993.

32. Hall-Mendelin S, Pyke AT, Moore PR, Mackay IM, McMahon JL, Ritchie SA et al. Assessment of local mosquito species incriminates Aedes aegypti as the potential vector of Zika virus in Australia. PLoS Negl Trop Dis. 2016;10:e0004959.

33. Huang YJ, Ayers VB, Lyons AC, Unlu I, Alto BW, Cohnstaedt LW, et al. Culex species mosquitoes and Zika virus. Vector Borne Zoonotic Dis. 2016;16:673-6.

34. Weger-Lucarelli J, Ruckert C, Chotiwan N, Nguyen C, Garcia Luna SM, Fauver JR, et al. Vector competence of American mosquitoes for three strains of Zika virus. PLoS NegI Trop Dis. 2016;10:e0005101.

35. Jupatanakul N, Sim S, Dimopoulos G. The insect microbiome modulates vector competence for arboviruses. Viruses. 2014;6:4294-313.

36. Lambrechts L, Chevillon C, Albright RG, Thaisomboonsuk B, Richardson $\mathrm{JH}$, Jarman RG, et al. Genetic specificity and potential for local adaptation between dengue viruses and mosquito vectors. BMC Evol Biol. 2009;9:160.

37. Stenn T, Peck KJ, Rocha Pereira G, Burkett-Cadena ND. Vertebrate hosts of Aedes aegypti, Aedes albopictus, and Culex quinquefasciatus (Diptera: Culicidae) as potential vectors of Zika virus in Florida. J Med Entomol. 2019:56:10-7.

38. Azmi SA, Das S, Chatterjee S. Seasonal prevalence and blood meal analysis of filarial vector Culex quinquefasciatus in coastal areas of Digha, West Bengal, India. J Vector Borne Dis. 2015;52:252-6.

39. Nunes VdN. Avaliação da metodologia de aspiração de mosquitos adultos para monitoramento da infestação por Aedes aegypti em área endêmica de dengue em Recife/PE. Recife: Aggeu Magalhães Institute; 2013.

40. Farjana T, Tuno N. Multiple blood feeding and host-seeking behavior in Aedes aegypti and Aedes albopictus (Diptera: Culicidae). J Med Entomol. 2013;50:838-46.

41. Barata EA, Costa Al, Chiaravalloti Neto F, Glasser CM, Barata JM, Natal D. Aedes aegypti (L.) population in an endemic area of dengue in Southeast Brazil. Rev Saude Publica. 2001;35:237-42 (In Portuguese).

42. Regis L, Silva-Filha MH, de Oliveira CM, Rios EM, da Silva SB, Furtado AF. Integrated control measures against Culex quinquefasciatus, the vector of filariasis in Recife. Mem Inst Oswaldo Cruz. 1995;90:115-9.

43. Cardoso BF, Serra OP, Heinen LB, Zuchi N, Souza VC, Naveca FG, et al. Detection of Oropouche virus segment $\mathrm{S}$ in patients and in Culex quinquefasciatus in the state of Mato Grosso, Brazil. Mem Inst Oswaldo Cruz. 2015;110:745-54.

44. Vasconcelos PF, Travassos Da Rosa JF, Guerreiro SC, Degallier N, Travassos Da Rosa ES, Travassos Da Rosa AP. 1st register of an epidemic caused by
Oropouche virus in the states of Maranhao and Goias, Brazil. Rev Inst Med Trop Sao Paulo. 1989;31:271-8 (In Portuguese).

45. Ahid SMM, Lourenco-de-Oliveira R. Mosquitos vetores potenciais de dirofilariose canina na Região Nordeste do Brasil. Rev Saúde Pública. 1999;33:560-5 (In Portuguese).

46. Weaver SC, Ferro C, Barrera R, Boshell J, Navarro JC. Venezuelan equine encephalitis. Annu Rev Entomol. 2004;49:141-74.

47. Eastwood G, Goodman SJ, Cunningham AA, Kramer LD. Aedes taeniorhynchus vectorial capacity informs a pre-emptive assessment of West Nile virus establishment in Galapagos. Sci Rep. 2013;3:1519.

48. Hunter FF. Linking Only Aedes aegypti with Zika virus has world-wide public health implications. Front Microbiol. 2017;8:1248.

49. IBGE. 2017. http://www. ibge.gov.br/home/. Accessed 4 Aug 2017.

50. Chow VT, Chan YC, Yong R, Lee KM, Lim LK, Chung YK, et al. Monitoring of dengue viruses in field-caught Aedes aegypti and Aedes albopictus mosquitoes by a type-specific polymerase chain reaction and cycle sequencing. Am J Trop Med Hyg. 1998;58:578-86.

51. Quick J, Grubaugh ND, Pullan ST, Claro IM, Smith AD, Gangavarapu K, et al. Multiplex PCR method for MinION and Illumina sequencing of Zika and other virus genomes directly from clinical samples. Nat Protoc. 2017;12:1261-76

52. Bolger AM, Lohse M, Usadel B. Trimmomatic: a flexible trimmer for Illumina sequence data. Bioinformatics. 2014;30:2114-20.

53. Langmead B, Salzberg SL. Fast gapped-read alignment with Bowtie 2. Nat Methods. 2012;9:357-9.

54. Robinson JT, Thorvaldsdottir H, Winckler W, Guttman M, Lander ES, Getz $\mathrm{G}$, et al. Integrative genomics viewer. Nat Biotechnol. 2011;29:24-6.

55. Thorvaldsdottir H, Robinson JT, Mesirov JP. Integrative Genomics Viewer (IGV): high-performance genomics data visualization and exploration. Brief Bioinform. 2013;14:178-92.

56. Guindon S, Dufayard JF, Lefort V, Anisimova M, Hordijk W, Gascuel O. New algorithms and methods to estimate maximum-likelihood phylogenies: assessing the performance of PhyML 3.0. Syst Biol. 2010;59:307-21.

57. Lefort V, Longueville JE, Gascuel O. SMS: Smart Model Selection in PhyML. Mol Biol Evol. 2017:34:2422-4.

58. Hordijk W, Gascuel O. Improving the efficiency of SPR moves in phylogenetic tree search methods based on maximum likelihood. Bioinformatics. 2005;21:4338-47.

59. Anisimova M, Gascuel O. Approximate likelihood-ratio test for branches: A fast, accurate, and powerful alternative. Syst Biol. 2006;55:539-52.

60. Katoh K, Rozewicki J, Yamada KD. MAFFT online service: multiple sequence alignment, interactive sequence choice and visualization. Brief Bioinform. 2017. https://doi.org/10.1093/bib/bbx108.
Ready to submit your research? Choose BMC and benefit from:

- fast, convenient online submission

- thorough peer review by experienced researchers in your field

- rapid publication on acceptance

- support for research data, including large and complex data types

- gold Open Access which fosters wider collaboration and increased citations

- maximum visibility for your research: over $100 \mathrm{M}$ website views per year

At BMC, research is always in progress.

Learn more biomedcentral.com/submissions 